\title{
Torque evolution and effects on alumina feedstocks prepared by various kneading sequences
}

\author{
Rong-Yuan $\mathrm{Wu}^{*}$, Wen-Cheng J. Wei \\ Institute of Materials Science and Engineering, National Taiwan University, Taipei, Taiwan 106, ROC \\ Received 4 February 1999; accepted 28 February 1999
}

\begin{abstract}
The effects of different kneading sequences on the homogeneity, strength and Weibull modulus of green density and sintered parts were studied. Polypropylene (PP), paraffin wax (PW) and stearic acid (SA) in a mass ratio of 25:70:5 mass\% were mixed with $\mathrm{Al}_{2} \mathrm{O}_{3}$ to produce feedstocks. Five different kneading sequences were implemented and analyzed using several techniques, including capillary and torque rheometries, Fourier transformed infrared spectroscopy (FTIR), differential scanning calorimetry (DSC) and pycnometry to reveal the properties of the feedstocks. Subsequently, the properties of injection molded samples subjected to the same solvent and thermal debinding conditions were observed. After sintering, the results of the fracture strength and Weibull modulus of $\mathrm{Al}_{2} \mathrm{O}_{3}$ strongly suggest that the kneading process closely control the homogeneity of feedstocks. The p3 process (kneading sequence, $\mathrm{Al}_{2} \mathrm{O}_{3}->$ PP- $>$ SA- $>$ PW) could produce the largest torque and homogeneous feedstock. The produced specimens showed the greatest average strength (371 MPa) and Weibull modulus (8.1). (C) 1999 Published by Elsevier Science Ltd. All rights reserved.
\end{abstract}

Keywords: $\mathrm{Al}_{2} \mathrm{O}_{3}$; Mechanical properties; Kneading; Injection molding; Shaping

\section{Introduction}

Ceramic injection molding (CIM) has rapidly developed in the past decade due to the capability of the near-net-shape processing of fine ceramic pieces. The advantages of the technique include dimensional accuracy, complex shaping capabilities, and suitability for mass production. ${ }^{1-4}$ Consequently, the process can reduce manufacturing costs. But CIM must overcome a variety of technical shortcomings, involving the complexity of the molding machinery and mold design, wide variant kneading processes, and a long binder extracting period.

Juang et al. ${ }^{5}$ shows that the quality of the mechanical strength of a ceramic injection molded part is relevant to the solid loading (55-60 vol\%) of feedstocks. The optimized solid content of $55 \mathrm{vol} \%$ gives the best Weibull modulus of 11.0 in fracture strength. Additionally, the fracture strength of sintered parts as reported by Chen and $\operatorname{Lin}^{16}$ is from 150 to $200 \mathrm{MPa}$ as a variation of stearic acid concentration in a $52 \mathrm{vol} \%$ solid content. Besides those, one of the important aspects in CIM is the kneading process which may affect the flow properties of

\footnotetext{
* Corresponding author.
}

a feedstock. Many reports ${ }^{3-5}$ show that the properties of sintering parts will be better if their feedstocks are produced homogeneously.

The kneading process is difficult to characterize because the properties of IM parts are influenced by many variables, including powder characteristics, solid content, effective surfactant agent, kneading equipment, and the type of binders used. Dow et al. ${ }^{3,4}$ adverted to a feedstock system containing a powder and single polymer. By decreasing the temperature and increasing rotor speed during the kneading process, a higher torque can be obtained, and can consequently break down the agglomerates in the powder. Takahashi et al. ${ }^{7,8}$ reported on how to reach a close "capillary state" under a critical solid loading resulting in excellent mechanical properties of IM parts.

Although the kneading process has gained the attention by ceramists in the past decade, little information is available on the effects of the additive sequence of multiple-component binders on the properties of alumina feedstocks. ${ }^{8-11}$ Moreover, many possible methods can be utilized to add the ingredients of multiple-component binders in the kneading step for the preparation of feedstocks. In this study, we consider the effects of the 
adding sequence of polymeric ingredients to the state of the dispersion in ceramic particle/polymer systems. The evolution of torque during kneading, the degradation of the binders, the physical properties of the IM part prepared by different powder/polymer batches were investigated according to the sequence of the addition of ingredients during kneading.

\section{Experimental procedure}

\subsection{Materials}

The raw materials used in this study include alumina powder, polypropylene (PP), paraffin wax (PW), stearic acid (SA) and $n$-heptane solvent. The alumina powder A-16SG is a commercial powder made by Alcoa Industrial Chemicals (Alcoa, USA). PP (Formosa Plastic, Taiwan) and PW (Nippon Serio, Japan) were used as the backbone-polymer and plasticizer, respectively, in the formulation. SA (Nacalai Tesque, Japan) as an interfacial agent could create an interfacial bridge between the powder and binder to enhance the compatibility of the binder system to $\mathrm{Al}_{2} \mathrm{O}_{3}$ powder. The solid content of the feedstock was in a volume of $56.6 \%$ for the overall constitution, in which the polymeric ingredients were in a mass ratio of PP:PW:SA $=25: 70: 5$.

\subsection{Processing}

\subsubsection{Kneading and granulation}

Kneading equipment with twin $\Sigma$-type blades (Ray-E Manufacture Co., Tainan, Taiwan) was used and operated at a rate of $35 \mathrm{rpm}$. In the beginning of the kneading process, alumina powder was preheated to $175^{\circ} \mathrm{C}$ in the kneader for half an hour. The details of five kneading sequences are listed and assigned from p1 to $\mathrm{p} 5$ as shown in Table 1. Based on the torque results, there are distinguished into three groups and five total sequences in this study. The $\mathrm{p} 1$ and $\mathrm{p} 2$ sequences belong to the low-torque kneading process, while $\mathrm{p} 3$, and $\mathrm{p} 4$ sequences are related to the high-torque process. The $\mathrm{p} 5$ sequence is in the middle. For example, in the p3 sequence, $\mathrm{PP}$ was first added into the preheated bowl with $\mathrm{Al}_{2} \mathrm{O}_{3}$ powder. After kneading for $60 \mathrm{~min}$, SA was added and the heater of the kneader was turned-off. The temperature of the kneader then decreased naturally. Ten minutes later, PW was added into the bowl step by step as the temperature of the kneader still remained over $140^{\circ} \mathrm{C}$. The dough-type mixture was then granulated as the temperature of the bowl decreased to $70^{\circ} \mathrm{C}$. The sequence of $\mathrm{p} 5$ was similar to the $\mathrm{p} 3$ except that the same amount of SA was pre-coated on $\mathrm{Al}_{2} \mathrm{O}_{3}$ powder by dissolving in $n$-heptane and co-drying in ambient temperature.

\subsubsection{Injection molding}

An injection-molding machine (CDC9000 SM50, CHEN HSONG, Co., Taiwan, ROC) was used and the IM pressures operated in four stages at 40, 40, 69 and 54 MPa were also used. The barrel temperatures of the IM machine from feeding to sprue side were 150, 150, 160 and $165^{\circ} \mathrm{C}$, and the temperature of the hot sprue of a mold was set at $130^{\circ} \mathrm{C}$. The mold temperature was $50^{\circ} \mathrm{C}$, and the mold had twin cavities with the dimensions of $4.00 \times 5.15 \times 49.95 \mathrm{~mm}^{3}$.

\subsubsection{Debinding and sintering}

Solvent and thermal debinding methods were used to remove the binders and to achieve a high debinding rate. An organic solvent $n$-heptane was selected for extracting soluble ingredients of PW and SA from the IM specimens. The solvent debinding for all specimens lasted for $2.5 \mathrm{~h}$ at $50^{\circ} \mathrm{C}$. In general, $80 \%$ (mass based) of the soluble ingredients could be extracted. After drying, the specimens were placed in a thermal-debinding furnace

Table 1

The details of five kneading sequences

\begin{tabular}{|c|c|c|c|c|c|}
\hline \multirow[t]{2}{*}{ Sequence } & \multicolumn{2}{|l|}{ Steps } & \multicolumn{2}{|c|}{$\left(\frac{\text { Added material }}{\text { temperature/time }}\right)$} & \\
\hline & $1 \mathrm{st}$ & $2 \mathrm{nd}$ & $3 \mathrm{rd}$ & 4 th & \\
\hline \multirow[t]{2}{*}{$\mathrm{p} 1$} & $\mathrm{Al}_{2} \mathrm{O}_{3}$ & $\mathrm{SA}$ & PW & $\mathrm{PP}$ & \\
\hline & $100^{\circ} \mathrm{C} / 0^{\mathrm{a}}$ & $100^{\circ} \mathrm{C} / 6$ & $100^{\circ} \mathrm{C} / 12$ & $175^{\circ} \mathrm{C} / 21-81$ & $50^{\circ} \mathrm{C} / 90$ \\
\hline \multirow[t]{2}{*}{ p2 } & $\mathrm{Al}_{2} \mathrm{O}_{3}$ & $\mathrm{PW}$ & $\mathrm{SA}$ & $\mathrm{PP}$ & \\
\hline & $100^{\circ} \mathrm{C} / 0$ & $100^{\circ} \mathrm{C} / 6$ & $100^{\circ} \mathrm{C} / 12$ & $175^{\circ} \mathrm{C} / 72$ & $50^{\circ} \mathrm{C} / 90$ \\
\hline \multirow[t]{2}{*}{ p3 } & $\mathrm{Al}_{2} \mathrm{O}_{3}$ & $\mathrm{PP}$ & SA & PW & \\
\hline & $175^{\circ} \mathrm{C} / 0$ & $175^{\circ} \mathrm{C} / 60$ & $<175^{\circ} \mathrm{C} / 66$ & $<175^{\circ} \mathrm{C} / 72$ & $50^{\circ} \mathrm{C} / 90$ \\
\hline \multirow[t]{2}{*}{$\mathrm{p} 4$} & $\mathrm{Al}_{2} \mathrm{O}_{3}$ & PP & PW & SA & \\
\hline & $175^{\circ} \mathrm{C} / 0$ & $175^{\circ} \mathrm{C} / 60$ & $175^{\circ} \mathrm{C} / 66$ & $175^{\circ} \mathrm{C} / 72$ & $50^{\circ} \mathrm{C} / 90$ \\
\hline \multirow[t]{2}{*}{ p5 } & $\mathrm{Al}_{2} \mathrm{O}_{3}$ coating $\mathrm{SA}$ & $\mathrm{PP}$ & PW & & \\
\hline & $175^{\circ} \mathrm{C} / 0$ & $175^{\circ} \mathrm{C} / 60$ & $175^{\circ} \mathrm{C} / 66$ & $50^{\circ} \mathrm{C} / 90$ & \\
\hline
\end{tabular}

a $100^{\circ} \mathrm{C} / 0$ means to add the material at $0 \mathrm{~min}$ and $100^{\circ} \mathrm{C}$ in kneading process. 
operated in air to $1000^{\circ} \mathrm{C}$. Subsequently, the specimens were heated at a rate of $10^{\circ} \mathrm{C} / \mathrm{min}$ to $1580^{\circ} \mathrm{C}$, then held for $1 \mathrm{~h}$ in air for sintering.

\subsection{Characterization}

\subsubsection{Torque and capillary rheometry}

Torque rheometry was self-assembled. A twin kneader (PBV-01, Japan) with a torque transducer (San-Ei mold, NEC, Japan) and signal amplifier were used. The amplifier (AS2103, NEC, Japan) transformed the measured torque to an electric message which could be recorded by PC. The volume of the mixing bowl was finally filled with the feedstock to about $57.5 \%$ of the kneader, identical to that used in the literature. ${ }^{8}$ In addition, a capillary rheometer (Rosand RH7, UK) was used to determine the pushing pressure exerted on the feedstocks during the test. The measurements were made at the same temperature of the feedstocks for injection molding.

\subsubsection{Spectroscopic analysis}

The changes of bonding structure of SA during thermal kneading were investigated using a Fourier transform infrared spectroscopy (FTIR-5300, JASCO, Japan) operated from 4000 to $400 \mathrm{~cm}^{-1}$. A differential scanning calorimeter (DSC-50, Shimadzu Co., Japan) operated from room temperature to $450^{\circ} \mathrm{C}$ at a heating rate of $10^{\circ} \mathrm{C} \mathrm{m^{-1 }}$ was used to detect the variation of heat either an exothermic or endothermic reaction during thermal degradation of the polymeric ingredients.

\subsubsection{Material properties}

The density of feedstocks was measured by a pycnometer (Ultrapycnometer-100, Quantachrome Co., NY). Green density of IM samples could also be obtained for comparison using a water replacement method (Archimedes' method). The sintered densities of IM bodies were measured according to ASTM372-73.

\subsubsection{Strength evaluation}

The fracture strength of the fired specimens was measured according to the JIS 1608 standard. ${ }^{18}$ The specimens were surface-ground using a 325-mesh diamond wheel and following the procedures specified in our previous work. ${ }^{19}$ A dynamic testing instrument (MTS810, MTS Co., USA) with upper and lower spans of 10 and $30 \mathrm{~mm}$ was used for the four-point bending test.

\section{Results and discussion}

\subsection{Properties of feedstocks}

The Torque, Time and Temperature $(\mathrm{T}-\mathrm{T}-\mathrm{T})$ diagrams of the feedstocks prepared in five kneading sequences are reported in Fig. 1. The T-T-T curves can be categorized into two groups: A lower-torque kneading which was produced by either $\mathrm{p} 1$ or $\mathrm{p} 2$ sequences, or a higher-torque kneading, produced by either $\mathrm{p} 3$, $\mathrm{p} 4$, or $\mathrm{p} 5$ sequences. The firstly group first added polymers of low molecular weight, e.g. PW or SA. So the curves of 11 and p2 still showed a low torque of $0.1 \mathrm{kgf}-\mathrm{m}$ in the initial kneading stage as shown in Fig. 1(a). The temperature decreased in the kneading stage of $\mathrm{p} 1$ or $\mathrm{p} 2$ proceeded about $72 \mathrm{~min}$, the torque increased to $0.6 \mathrm{kgf}-\mathrm{m}$ as soon as PP was added. The viscosity of the mixture increased as the cold component was added. The torque of the $\mathrm{T}-$ $\mathrm{T}-\mathrm{T}$ curves in Fig. 1(a) increased accordingly due to the addition of the new component.

The kneading in p3 or p4 sequence in Fig. 1(b) started from a high torque which was greater than $3 \mathrm{kgf}-\mathrm{m}$, then reduced to a stable value before SA and PW were added. The p3 kneading process reached a stable torque of $2.8 \pm 0.1 \mathrm{kgf}-\mathrm{m}$ after $40-50 \mathrm{~min}$ when the ingredients still had $\mathrm{Al}_{2} \mathrm{O}_{3}$ and $\mathrm{PP}$. After added $\mathrm{SA}$ at $60 \mathrm{~min}$, the torque of $\mathrm{p} 3$ or $\mathrm{p} 4$ reduced dramatically. The torque declined further when PW was added at $66 \mathrm{~min}$.

The torque evolution of $\mathrm{p} 5$ is similar to that of $\mathrm{p} 3$ or $\mathrm{p} 4$. But the value of the torque is relatively small in the first $60 \mathrm{~min}$. The pre-coated $\mathrm{SA}$ on $\mathrm{Al}_{2} \mathrm{O}_{3}$ reduced the viscosity of $\mathrm{PP}$ and resulted in a stable torque evolution.

Takahashi et al. ${ }^{8}$ described four different patterns of torque-time curves during the kneading of ceramic and

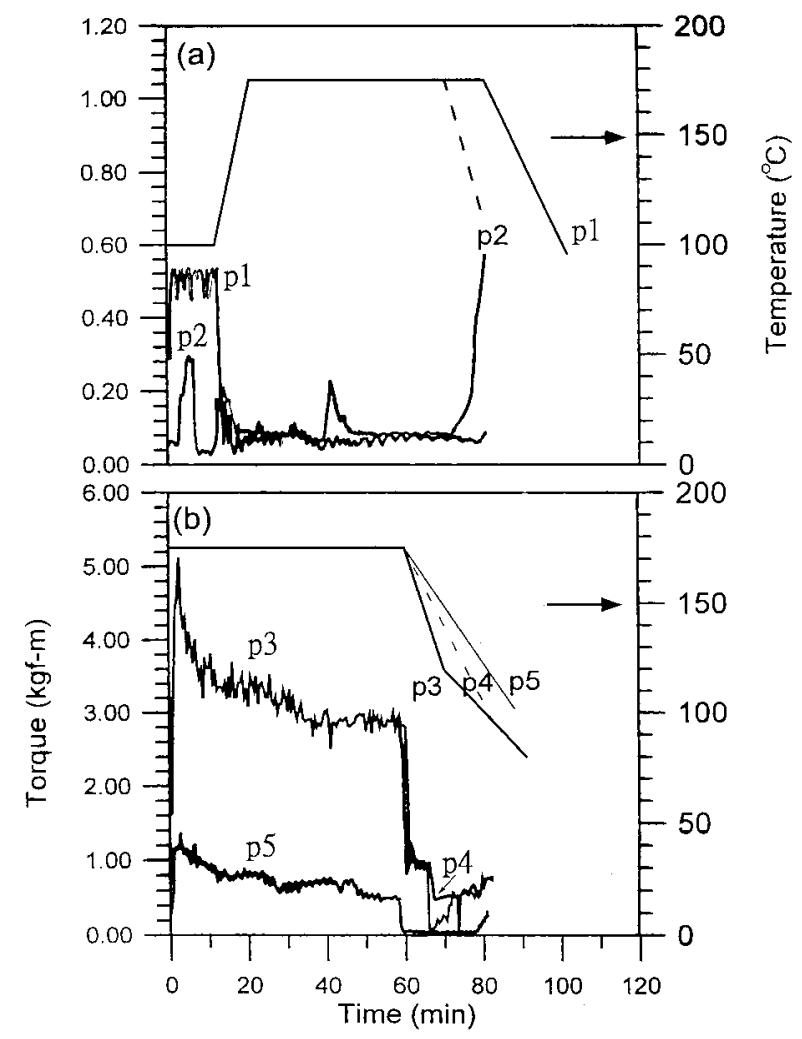

Fig. 1. Torque, time and temperature (T-T-T) diagrams of (a) p1, p2 and (b) p3, p4 and p5 kneading sequences. 
single polymer. Pattern II, which shows the torque decrease during kneading, is often observed. In addition, the torque-time curves representing the powder mixed with single or multiple polymeric components have shown different degrees of variation. The longer the kneading lasts, the less the scattering of the torque value will be. Additionally, a wider scattering of the torque in the initial stage of p3 and p4 kneading compared to that of $\mathrm{p} 5$ is also noted, implying inhomogeneous solid content or temperature distribution in the feedstocks.

Fig. 2 shows the DSC thermal analytic diagrams of the feedstocks after a complete kneading process. In Fig. 2(a), all five feedstocks show endothermic peaks at $43 \pm 1, \quad 59 \pm 0.5$ or $144 \pm 3^{\circ} \mathrm{C}$, corresponding to the melting points of $\mathrm{PW}, \mathrm{PP}$ and SA. As the thermal decomposition temperatures rise above $200^{\circ} \mathrm{C}$, the exothermic dissociation of $\mathrm{p} 1, \mathrm{p} 4$ and $\mathrm{p} 5$ involves several peaks which show wider distribution of the exothermic reaction. In comparison, the thermal decomposition of p2 has one major dissociation peak above $200^{\circ} \mathrm{C}$. The reasons for those being only one peak are due mainly to the solubility of the multiple-component binder in kneading. The feedstocks in $\mathrm{p} 2$ have a better solid solution from a molecular aspect. Lin and $\mathrm{Wei}^{23}$ studied the thermal decomposition behavior of different size grading IM zirconia parts. When the particle size is larger $(\cong 60 \mu \mathrm{m})$, low shear force was produced by kneading, and the thermal decomposition of the feedstock had one major dissociation peak greater than $200^{\circ} \mathrm{C}$, because fibrous PP still existed in the feedstock when prepared under a smaller kneading stress. If the particle size was smaller $(\cong 1 \mu \mathrm{m})$ in a reverse condition, the thermal decomposition of feedstock revealed several dissociation peaks. The binders of the feedstocks became rich in PP, but lean in $\mathrm{PW}+\mathrm{SA}$ content after solvent debinding. The DSC diagram [Fig. 2(b)] of the solvent-debinded specimens reveals roughly two exothermic peaks at the temperatures greater than $200^{\circ} \mathrm{C}$, one dissociation peak being in the temperature range of 200 to $240^{\circ} \mathrm{C}$ and the other between 340 and $360^{\circ} \mathrm{C}$. The peaks represent the exothermic reaction of the dissociation of PP (major ingredient) and PW. The DSC decomposition behaviors of $\mathrm{IM} /$ solvent debinding specimens using various kneading processes show no observable influence on PP. Our results reveal that the states of PW are the reasons for the difference in Fig. 2(a). A further investigation concerning the effects of shear force on the homogeneity of PW in the plastic composition is presented in the following sections.

Fig. 3 shows the FTIR spectra of the feedstocks after kneading for 80 min using different kneading sequences. It is noted that all specimens from the kneading sequences have a peak shift from 1700 to $1560 \mathrm{~cm}^{-1}$ representing the absorption of $\mathrm{SA}$ on $\mathrm{Al}_{2} \mathrm{O}_{3}$ to form $\mathrm{C}-$ $\mathrm{O}-\mathrm{Al}$ bonds. The proposed explanation ${ }^{16}$ is that SA was
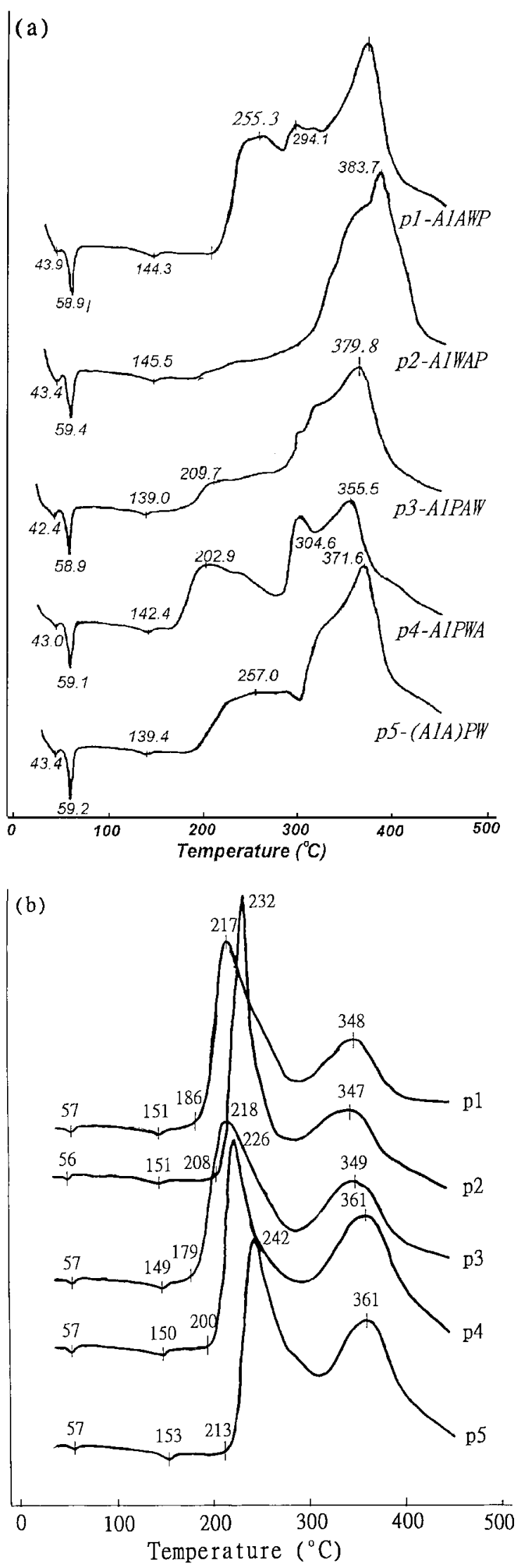

Fig. 2. DSC thermal analytic diagram of (a) the feedstock after kneading for $80 \mathrm{~min}$; (b) the IM part after solvent debinding. 


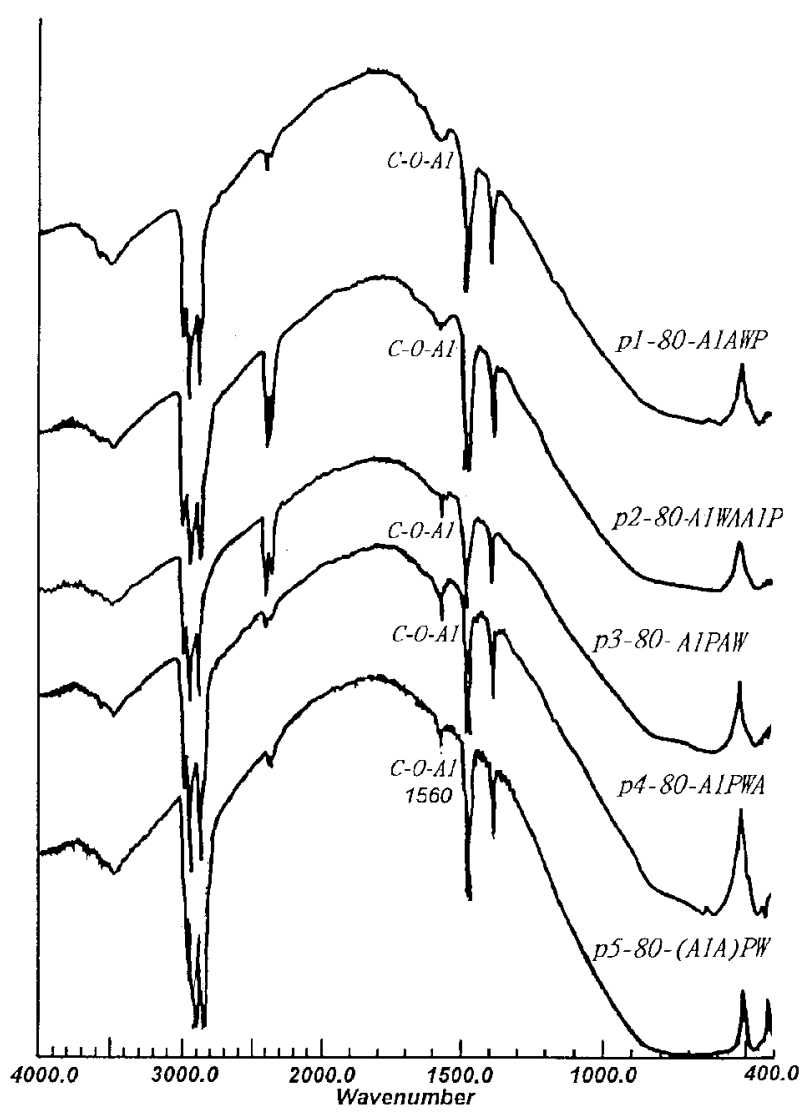

Fig. 3. FTIR spectra of the feedstocks after kneading for $80 \mathrm{~min}$.

adsorbed on the alumina surface forming acid salts due to its carboxylate ions $\left(\mathrm{COO}^{-}\right)$, thus, a new peak appears at $1560 \mathrm{~cm}^{-1}$. However, SA $\left(\mathrm{C}_{17} \mathrm{H}_{35} \mathrm{COOH}\right)$ can be absorbed on the $\mathrm{Al}_{2} \mathrm{O}_{3}$ surface in all sequences. However, the intensity of $\mathrm{C}-\mathrm{O}-\mathrm{Al}$ adsorption at 1560 $\mathrm{cm}^{-1}$ decreases after solvent debinding of the specimens. It is believed, then, the absorption peak of $1560 \mathrm{~cm}^{-1}$ resulted from a solvent shift of SA, but not from a thermal decomposition of PP or PW during kneading. ${ }^{10-15}$

The green density and normalized standard deviation (NDS\%) of the mixed feedstocks are shown in Fig. 4. The testing feedstocks were sampled randomly 10 times for the statistic analysis. The samples prepared from $\mathrm{p} 2$ and $\mathrm{p} 3$ show a smaller value of NDS\% than did the others. A stable and homogenous feedstock is favored for CIM.

Pressure fluctuation through a small capillary can reveal the homogenous character of the feedstocks. The fluctuation in the force-time curves (Fig. 5) indicates the positions of low or high pressures representing binder-rich or solid-rich feedstock, respectively. If the binders are more homogeneous in the feedstock, the behavior of the melted feedstock flowing through capillary changes dramatically. ${ }^{2}$ Fig. 5 shows that the force-time $(\mathrm{F}-\mathrm{t})$ curves of $\mathrm{p} 4$ and $\mathrm{p} 5$ have a significant fluctuation on capillary force. Bohm et al. ${ }^{7}$ reported that a homogenous feedstock would have a

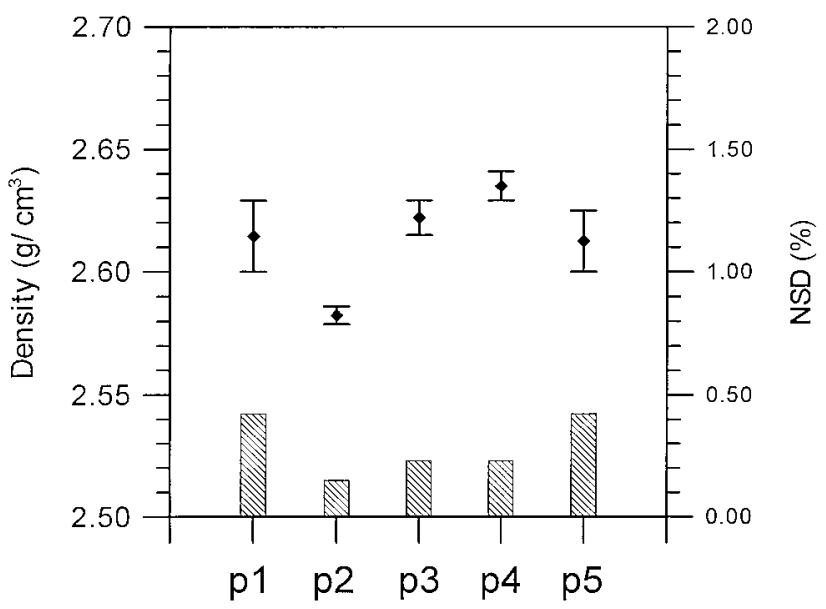

Fig. 4. Relative density and normalized standard deviation (NDS\%) of prepared feedstocks by different mixing sequences. Note that the statistics are based on 10 samples for each mixing sequence.

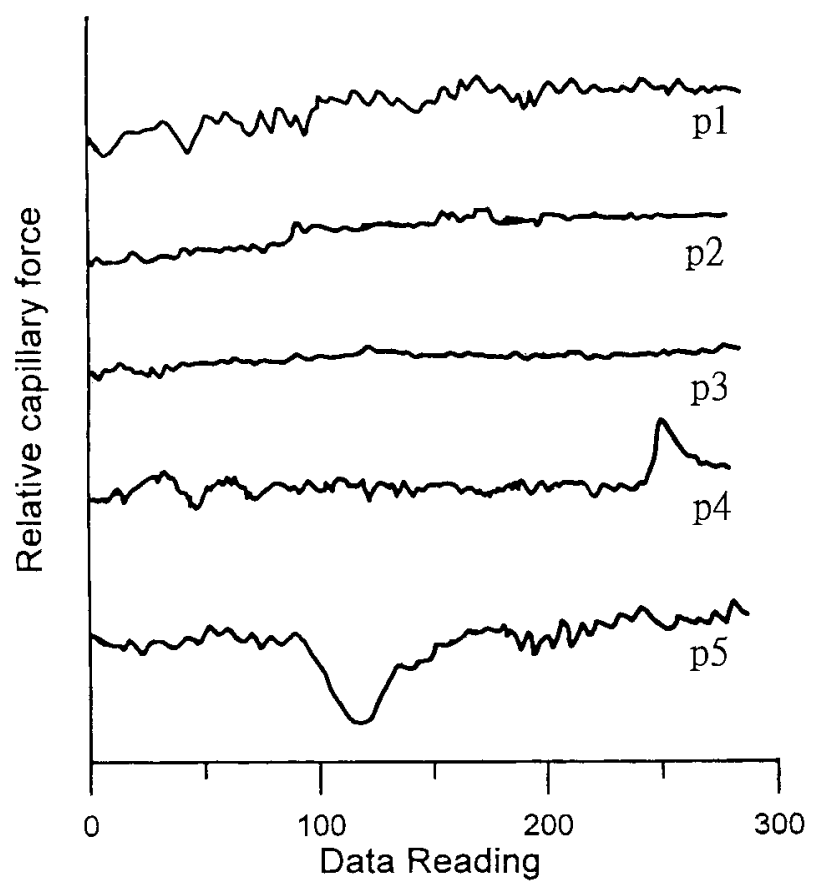

Fig. 5. Relation of capacity force to testing time of the feedstocks prepared by various mixing sequences.

small variation of capillary pressure versus testing time. The reason for a lower force of greater pressure drop is due to the voids or polymer-rich content in the testing feedstock flowing through the capillary, as in the curve of p5 in Fig. 5. The opposite case shown in the curve of $\mathrm{p} 4$ is because a feedstock of solid-rich requires a higher push force to flow. In contrast, the F-t curve of $\mathrm{p} 2$ and $\mathrm{p} 3$ is flat (less fluctuation) indicating a uniform feedstock prepared using a good kneading sequence. The p2 and p3 kneading processes provide different shear stress to enhance the dispersion condition. The $\mathrm{p} 3$ process offers a strong torque, resulting in good dispersion and good solubility 
Table 2

Dimension and variation of green, solvent/thermal debinded and sintered bodies by different kneading sequences.

\begin{tabular}{|c|c|c|c|c|c|}
\hline \multirow[t]{2}{*}{ State of IMP sample } & \multicolumn{5}{|c|}{ Kneading sequence } \\
\hline & $\mathrm{p} 1$ & $\mathrm{p} 2$ & p3 & $\mathrm{p} 4$ & p5 \\
\hline Green & $50.48 \pm 0.06$ & $50.44 \pm 0.02$ & $50.66 \pm 0.06$ & $50.43 \pm 0.03$ & $50.44 \pm 0.02$ \\
\hline Solvent debinded & $49.49 \pm 0.04$ & $49.42 \pm 0.03$ & $49.57 \pm 0.05$ & $49.32 \pm 0.03$ & $49.43 \pm 0.02$ \\
\hline Solvent + thermal debinded & $49.25 \pm 0.02$ & $49.24 \pm 0.02$ & $49.31 \pm 0.04$ & $49.25 \pm 0.02$ & $49.24 \pm 0.02$ \\
\hline Sintered & $43.35 \pm 0.10$ & $41.51 \pm 0.03$ & $41.58 \pm 0.05$ & $41.55 \pm 0.03$ & $41.78 \pm 0.03$ \\
\hline
\end{tabular}

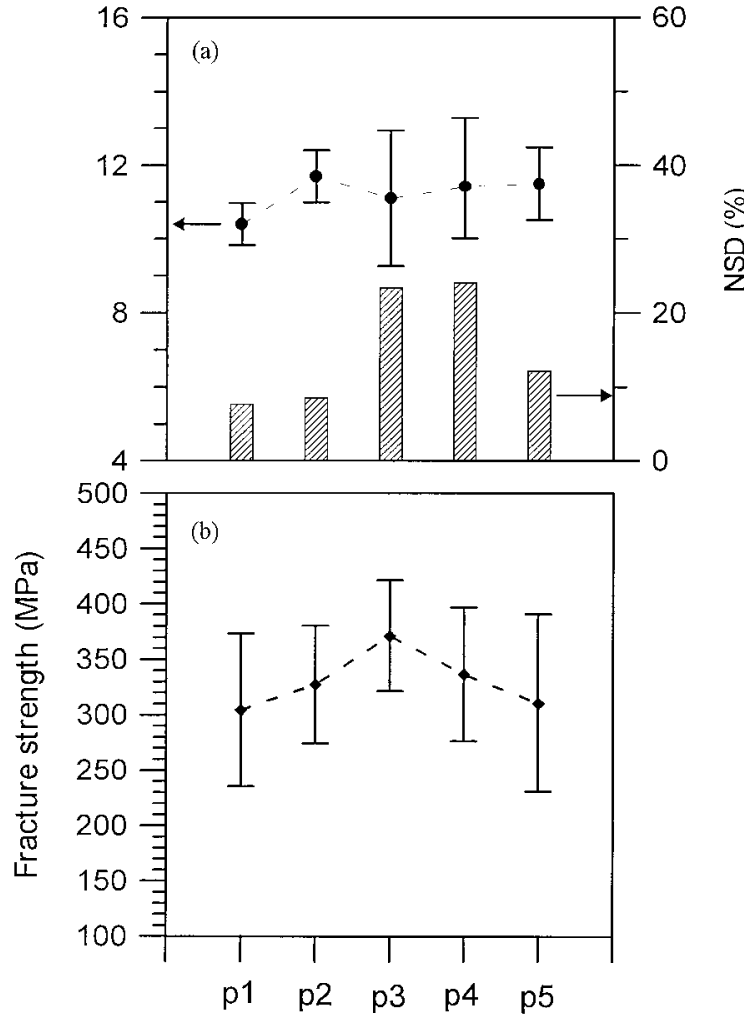

Fig. 6. Fracture strength of (a) green (b) sintered parts prepared by different mixing sequences.

of the multiple-component binders. Although the $\mathrm{F}-\mathrm{t}$ curve of $\mathrm{p} 3$ is nearly identical to that of $\mathrm{p} 2$, the former has consisted of greater feedstock density than that of the $\mathrm{p} 2$ kneading process.

\subsection{Physical properties of IM parts}

Dimensional variation in green, solvent/thermal debinded or sintered bodies is shown in Table 2. The variation of the part length is not significantly different among these specimens in various processing stages. Only one exception is noted, namely the sintering parts of $\mathrm{p} 1$ which show a 0.10 standard deviation, one time higher than the ordinary values, 0.02 to 0.06 . Kneading processes are not a major factor influencing the dimension of IM parts in CIM.

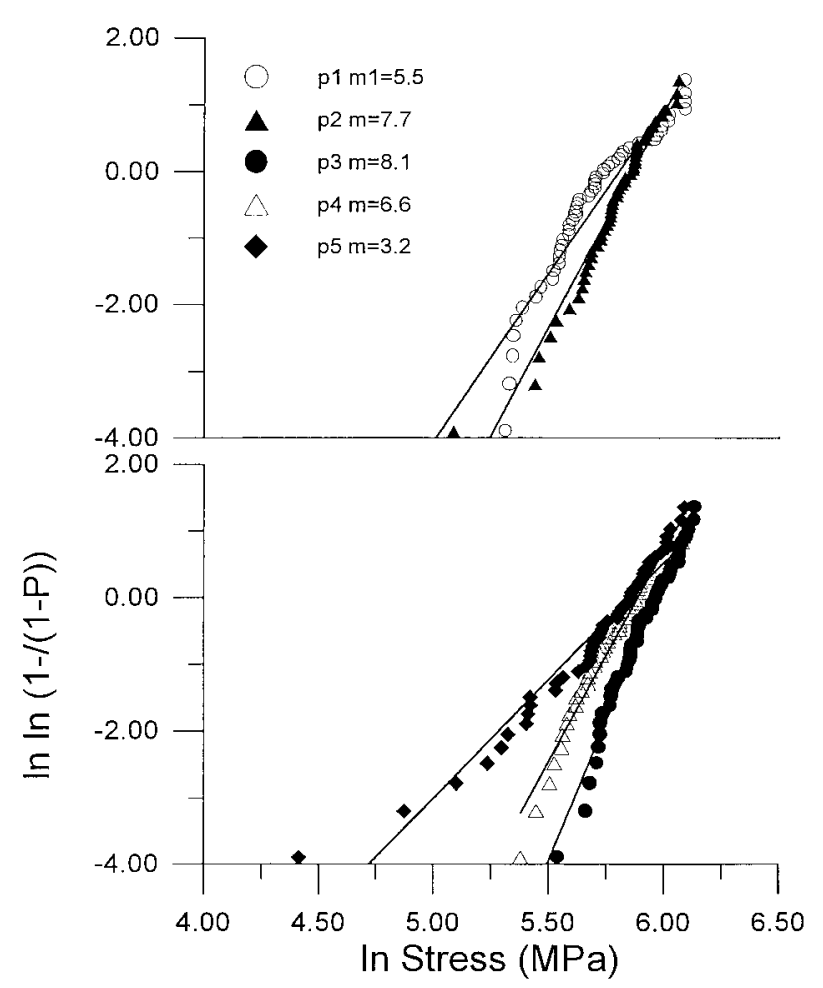

Fig. 7. Weibull distribution of sintered bodies by (a) p1 and p2; (b) p3, $\mathrm{p} 4$ and $\mathrm{p} 5$.

The value and variation of the fracture strength of green and sintered bodies prepared by various mixing sequences are shown in Fig. 6. The average green strengths of these IM parts are about $11 \mathrm{MPa}$. However, the variation of green strength of specimens $\mathrm{p} 2$ and $\mathrm{p} 3$ show a great difference. The average fracture strength of the sintered $\mathrm{p} 3$ test bars is $371 \mathrm{MPa}$, a value $25 \%$ greater than that of $\mathrm{p} 1$. However, the error bars of the strength values on green and sintered parts are indeed overlapping. It is hard to state that there is a significant difference among these green and sintered strengths in Fig. 6. But the results of the bending strength still can be categorized into two groups: IM samples prepared by p1, p2, p5 are lower in strength, and those higher by $\mathrm{p} 3$ and $\mathrm{p} 4$. The reason can be the adding sequence of PW or SA, the low-molecularweight ingredient, in the kneading process. When the 
PW or SA is added prior to PP, the bending strength of the green parts is lower, i.e. p1, p2 and p5. The bending strength and Weibull modulus (m) of sintered alumina have been conclusively reported in the literature; ${ }^{20}$ that are $380 \mathrm{MPa} \pm 20 \%$ and $11 \pm 4$, respectively, tested at room temperature. This study using IM technique reports the strength and Weibull modulus of alumina to be lower, 310-330 MPa and 7-11, respectively.

Table 3

Relation to different kneaded sequences on green density, sintering density, fracture strength and Weibull distribution.

\begin{tabular}{lllll}
\hline Process & Green density $\left(\mathrm{g} / \mathrm{cm}^{3}\right)$ & Relative sintering density (T.D.\%) & Fracture strength (MPa) & Weibull modulus (m) \\
\hline p1 & $2.580 \pm 0.02$ & $97.4 \pm 0.5$ & $297 \pm 65$ & 5.5 \\
p2 & $2.626 \pm 0.07$ & $98.3 \pm 0.3$ & $335 \pm 51$ & 7.7 \\
p3 & $2.608 \pm 0.01$ & $97.9 \pm 0.6$ & $371 \pm 50$ & 8.1 \\
p4 & $2.616 \pm 0.009$ & $98.4 \pm 0.4$ & $339 \pm 61$ & 6.7 \\
p5 & $2.622 \pm 0.007$ & $97.8 \pm 0.4$ & $314 \pm 81$ & 3.2 \\
\hline
\end{tabular}
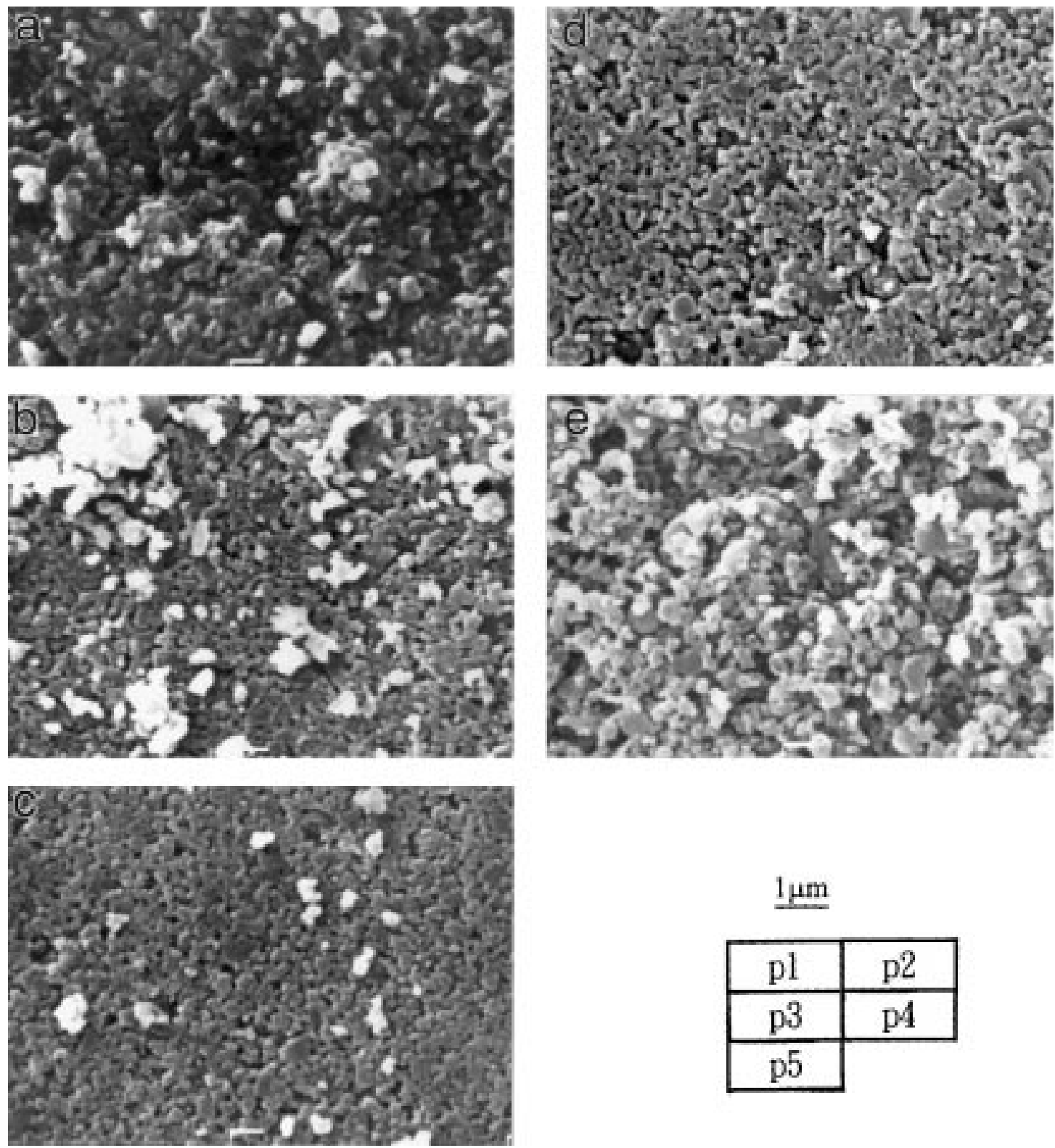

$1 \mu \mathrm{m}$

\begin{tabular}{|l|l|}
\hline $\mathrm{p} 1$ & $\mathrm{p} 2$ \\
\hline $\mathrm{p} 3$ & $\mathrm{p} 4$ \\
\hline $\mathrm{p} 5$ & \multicolumn{2}{|c}{} \\
\cline { 2 - 2 } &
\end{tabular}

Fig. 8. Surface morphologies of samples prepared by various mixing sequences and after solvent/thermal debinded. 
The Weibull plot of the fracture strength of the sintered bodies is shown Fig. 7. The modulus (m) of $\mathrm{p} 1$ and p5 is 5.5 and 3.2, respectively, the worst cases among the testing samples. These two sets of specimens have the same sequence of $\mathrm{SA}$ addition. It is of concern that a long period kneading at $170^{\circ} \mathrm{C}$ (Fig. 1) might result in a loss of SA. The other specimens in kneading processes of $\mathrm{p} 2$, $\mathrm{p} 3$ or $\mathrm{p} 4$ show greater m values (6.6 to 8.1) which means these kneading processes may form similar defects. The characterization of fracture origins of the last three specimens reveals the agglomeration of powder is the major defect.

The error of the Weibull modulus based on 40 testing specimens is estimated using Weibull statistics and shows a $\max \pm 6 \%$ variation of the modulus. ${ }^{21}$ Wei et al. ${ }^{22}$ reveals that the feedstocks prepared by an inadequate mixing process may produce binder segregation in IM parts resulting in large circular cracks induced by differential shrinkage. The strength distribution shows a two-mode character in Weibull plot. Data points of poor strength degrade the values of the Weibull modulus. The results imply that an adequate mixing sequence can improve the Weibull distribution of the strength.

Table 3 is the summary of the green density, sintered density, fracture strength $(\sigma)$ and Weibull modulus of the samples made by using different kneading sequences. The data in Table 3 exhibits no close relationship between the green density and the bending strength of the sintered parts, and no close relationship exists between the fired density and the bending strength. We believe that the densities of five specimens are in the range of $98 \pm 1 \%$ theoretical density (T.D.). The states of the porosity and large defects in fact control the fracture strength of the testing specimens.

The Weibull modulus of $\mathrm{p} 3$, as shown in Table 3, is 8.1, greater than the others. Although p2 and p3 were prepared with different mixing sequences and the feedstocks were mixed under various torques, the modulus of p2 and p3 is similar in mechanical properties, mainly due to the distribution of the backbone PP in the feedstocks. Mutsuddy ${ }^{10}$ reports that binder ingredients have good compatibility. So, according to the results of $4 / 22$ and 5/36, we analogized them. The kneading of PP in association with the breakdown of the agglomeration of $\mathrm{Al}_{2} \mathrm{O}_{3}$ powders is not only determined by the mixing torque, but by the final mixing state of all the polymeric ingredients.

Fig. 8 shows the microstructure on the surfaces of the IM samples after thermal debinding. According to the surface microstructure, the information concerning the homogeneity of the IM parts can be obtained. If the feedstock remains in an inhomogeneous state, the microstructure would be preserved through the solvent and thermal debinding steps. ${ }^{22}$ Non-uniform distribution of polymer and poor packing density likely induce flaws in the green parts. The experimental results show that the samples prepared in the $\mathrm{p} 1$ or $\mathrm{p} 5$ process after solvent debinding exhibit large voids of several $\mu \mathrm{m}$ in diameter and particle clusters. In comparison, the microstructure in Fig. 8(b) and (c) shows a better powder packing state with less agglomeration. After the sintering process, the microstructure of these sintering samples all exhibit a nearly identical grain size of $3.5 \mu \mathrm{m}$. Therefore, the bending strength is not controlled by grain size. The results imply that kneading processes generate distinct agglomeration and porous states in the powder. Thus the sintering density and the grain size are not relevant to the bending strength of the IM samples under different kneading processes.

\section{Conclusion}

The effects of different kneading sequences on the injection molding of alumina feedstocks have been investigated. The results show:

1. The mixing sequence of $\mathrm{p} 3$ produces well-mixing feedstocks. The procedures include preheating $\mathrm{Al}_{2} \mathrm{O}_{3}$ powder, then mixing with $\mathrm{PP}$ and later adding SA and PW. The feedstock of p3 exerts a higher torque and a small variation of capillary force based on a short kneading period. The variation of the density of feedstocks and the dissociation behavior of polymeric ingredients on thermal debinding are closely related to the kneading factors.

2. The sintered samples have a fired density 97.4 $98.4 \%$ T.D. in a standard deviation of $0.3-0.5 \%$ T.D. The bending strengths are 297-371 MPa with the standard deviation of 50-65 MPa. The Weibull modulus of fracture strength of sintered specimens is between 3.2 and 8.1. Therein, the best bending strength and Weibull modulus are found in the samples of $\mathrm{p} 3$. The results imply that agglomeration and a porous state can be generated under different kneading sequences. The defects, which can be retained through debinding and sintering stages, control the mechanical properties of the sintered samples.

3. Low-melting-point surfactant SA has a negative effect on the properties of feedstocks if it is added prior to PP and PW. Two specimens, prepared by p1 and p5, show greater variety in the physical properties of green and sintered samples.

\section{Acknowledgements}

The authors would like to thank the National Science Council for the funding given under contract no. NSC87-2216-E-002-034. 


\section{References}

1. Edirisinghe, M. J., Shaw, M. H. and Tomkins, K. L., Flow behavior of ceramic injection molding suspensions. Ceramic International, 1992, 18, 193-200.

2. Raman, R., Slike III, W. and German, R. M., Experimental evaluation of the mixing process for the preparation of feedstock for powder injection molding. Ceram. Eng. Sci. Proc., 1993, 14(11-12), 166-186.

3. Dow, J. H., Sacks, M. D. and Shenoy, A. V., Dispersion of alumina particles in the polyethylene melts, Ceramic Powder Science III, Edited by G. L. Messing et al., The American Ceramic Society, Westerville, OH, 1990, 431-442.

4. Dow, J. H., Sacks, M. D. and Shenoy, A. V., Dispersion of ceramic particles in the polymer melts. Ceramic Powder Science, Edited by G. L. Messing et al., The American Ceramic Society, Westerville, OH, 1988, 1(A), 380-388.

5. Juang, H. Y. and Hen, M. H., Effect of solid content on processing stability for injection molding of alumina evaluated by Weibull statistics. J. Ceram. Soc. Jpn., Int. Edition, 1995, 103, 436-439.

6. Goodrich, J. E. and Porter, R. S., A rheological interpretation of torque-rheometer data. Polymer Engineering and Science, 1967, 7, 45-51.

7. Takahashi, M., Suzuki, S., Nitanada, H. and Arai, E., Mixing and flow characteristics in the alumina/thermoplastic resin system. J. Am. Ceram. Soc., 1988, 71(12), 1093-1099.

8. Takahashi, M., Kihira, H., Ota, T. and Suzuki, S., Mixing behavior in the ceramic oxide/thermoplastic resin system near CPVC. J. Ceram. Soc. of Japan, Int. Edition, 1993, 101, 665-670.

9. Markhoff, C. J., Mutsuddy, B. C. and Lennon, J. W., A method for determining critical ceramic powder volume concentration in the plastic forming of ceramic mixing. In Advances in Ceramics, vol. 9, ed. J. Mangels. Am. Ceram. Soc., Columbus, OH, 1984, pp. 246-250.

10. Mutsuddy, B. C. and Ford, R. G., Ceramic Injection Molding. Chapman and Hall, London, 1995, pp. 278-282.
11. Paul Lin, S. T. and German, R. M., The influence of powder loading and binder additive on the properties of alumina injection-moulding blends. J. Mater. Sci., 1994, 29, 5367-5373.

12. German, R. M., Powder Injection Molding. Metal Powder Ind., Fed., Princeton, NJ, 1990.

13. Fowes, F. M. and Tischler, D. O., Acid-base complexes of polymers. J. Polym. Sci. Poly. Chem. Ed., 1984, 22(3), 547-566.

14. Pavia, D. L., Lampman, G. M. and Kriz, P. L., Introduction to Spectroscopy, 2nd edn. Bellingham, Saunders College, 1996.

15. Lin, S. T. and German, R. M., Interaction between binder and powder in injection moulding of alumina. J. Mater. Sci., 1994, 29, 5207-5212.

16. Chen, T. Y. and Lin, S. T., Effect of stearic acid on the injection molding of alumina. J. Am. Ceram. Sec., 1995, 78(10), 2746-2752.

17. Bohm, H. and Blackburn, S., Effect of mixing procedure on fine alumina paste extrusion. British Ceramic Transactions, 1994, 93(5), 169-170.

18. JIS R1608, Testing Method for Flexural Strength (Modulus of Rupture) of High Performance Ceramic.

19. Chyr, B. C., Wei, W. and Koo, C. H., Flexural strength and surface grinding properties of alumina. Chin. J. Mat. Sci., 1993, 25(3), 173-180.

20. Munro, R. J., Evaluated material properties for a sintered a-alumina. J. Am. Ceram. Soc., 1997, 80(8), 1919-1928.

21. Baratta, F., Ruimn, G. and Matthews, W., Errors associated with flexure testing of brittle materials, US Army Mat. Tech. Lab., Mass report, MTL, TR87-35, July 1987.

22. Wei, W. C. J., Tasi, S. J. and Hsu, K. C., Effect of mixing sequence on alumina prepared by injection molding. $J$. Euro. Ceram. Soc., 1998, 18, 1445-1451.

23. Lin, Y. P., The character of injection molding and mechanical properties of zirconia. Master thesis, National Taiwan University, 1997. 